\title{
Dual Band E and L Shaped Antenna Design with Compact Radiator for 2.5/5.2/5.8 GHz WLAN Application- A Review
}

\author{
Ramnath Narhete \\ M.Tech. Research Scholar \\ NIIST,Bhopal(M.P.)
}

\author{
Saket Kumar \\ Assistant Professor \\ NIIST,Bhopal(M.P.)
}

\author{
Puran Gour \\ Assistant Professor \\ NIIST,Bhopal(M.P.)
}

\begin{abstract}
In this Paper is Present of Dual-band antenna with a compact radiator for 2.4/5.2/5.8 proposed by optimizing its resonant frequency, Bandwidth of operation and radiation frequency using genetic algorithm. The antenna consists L-shaped and E-shaped radiating element to generate two resonant mode for dual band operation. The above techniques have been successfully used in many applications on communication. Dual band antenna with compact radiator for $2.4 / 5.2 / 5.8 \mathrm{GHz}$ WLAN application design and radiator size only width $8 \mathrm{~mm}$ and length is $11.3 \mathrm{~mm}$ [1]. The antenna can we used for various application in field of communication. Genetic algorithm will be used to design the antenna and impedance matching network.
\end{abstract}

\section{Keywords}

Genetic Algorithm, Dual band E and L, WLAN

\section{INTRODUCTION}

Now days is the wireless local area network (WLAN) is one of the most popular networks for accessing of the life. The WLAN uses a lower frequency band, $2.4-2.484 \mathrm{GHz}$, for the $802.11 \mathrm{~b} / \mathrm{g}$ standards, and higher frequency bands, 5-6 GHz, for the 802.11a standard. As the demand for smaller sizes of wireless devices increases, antennas designers are making tremendous efforts in attempts to reduce the physical sizes of the antennas, yet covering all the three operation bands. Currently life is going too fast. All people addicted of digital technology and all technology work wireless. So antenna design is best area of interest in this time for the Growth of wireless communication. In this paper proposed antenna design with the help of genetic algorithm. Try to design best antenna for finding of minimal and maximal position of the objective function use genetic algorithm. Genetic algorithm is very different from most of traditional optimization methods.

The performance of microstrip patch antennas can be increase by using different techniques such as by changing dielectric material, feed point, height of dielectric, slot dimensions, structure of patch as well as ground plane etc. In most of microstrip patch antenna narrow bandwidth [2] is a major problem. There are multiple choices of techniques to overcome this drawback. Designing slot on radiating patch's surface is one of the popular techniques for increasing the impedance bandwidth of patch antenna. The slot on the patch's surface affects the radiation characteristics of antenna [3]. In this communication [4] a microstrip E and L shaped with dual band is proposed. Because of the slot design on the patch's surface enhanced bandwidth of antenna is achieved. The proposed antenna is simulated by using CST simulator and MATLAB which is based on Genetic Algorithm.

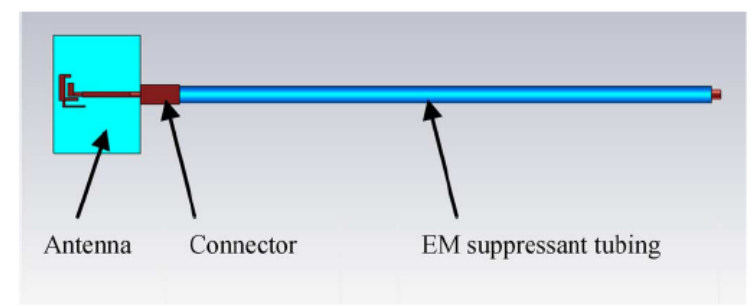

Fig.1 Proposed model of antenna

Therefore, due to the necessary length of monopole for resonating in the lower band, this procedure conducts to a relatively large antenna size. Various procedures have been introduced to decrease the size of the monopole accountable for the lower band. For example, in [1]-[3], the monopoles accountable for the lower band were bent to various shapes for size reduction.

\section{LITERATURE SURVEY}

A survey on "Dual-Band Antenna with Compact Radiator for 2.4/5.2/5.8 GHz WLAN Applications Using Genetic algorithm" has been performed. Previously, lots of ideas have been given by the researches to design of antenna. They have been implemented techniques of, 
Table: 1 Literature Survey

\begin{tabular}{|c|c|c|c|c|}
\hline Year & Vol(60) No.12 Dec2012 & Vol(58) N0.12 Dec 2010 & Vol(57)No.12 Dec 2009 & ICCCT2010 \\
\hline Publication & IEEE & IEEE & IEEE & ICCCT10 \\
\hline Topic & $\begin{array}{c}\text { Dual Band antenna with } \\
\text { compact Radiator for } \\
\text { 2.4/5.2/5.8 GHz WLAN } \\
\text { Application }\end{array}$ & $\begin{array}{l}\text { Design of compact Dual } \\
\text { Wide band antenna with } \\
\text { assembled monopoles }\end{array}$ & $\begin{array}{l}\text { Meandered T-shaped } \\
\text { Monopole Antenna }\end{array}$ & $\begin{array}{l}\text { Micro Strip antenna } \\
\text { optimization using } \\
\text { genetic Algorithms }\end{array}$ \\
\hline Res.Freq. & $2.4,5.2,5.8 \mathrm{GHz}$ & $\begin{array}{c}2.4,5.2,5.8 \mathrm{GHz} \text { WLan } \\
\text { 2.5,3.5,5.5 WiMax }\end{array}$ & $2.45,5.2,5.8 \mathrm{GHz}$ & $3-18 \mathrm{GHz}$ \\
\hline Substrate & FR-4 & FR-4 & FR-4 & Duroid \\
\hline $\begin{array}{l}\text { Dielectric } \\
\text { Constant }\end{array}$ & 4.4 & 4.4 & 4.4 & 2.39 \\
\hline $\begin{array}{l}\text { Total } \\
\text { Height }\end{array}$ & $0.8 \mathrm{~mm}$ & $1.6 \mathrm{~mm}$ & $1.6 \mathrm{~mm}$ & $1.578 \mathrm{~mm}$ \\
\hline Simulator & Satimo Starlab & HFSS & IE3D & IE3D \\
\hline
\end{tabular}

In this paper [1] a new dual band antenna was proposed and analyzed. Such type of antenna had compact radiator for 2.4/5.2/5.8 GHz WLAN application. Such antenna was constructed on a $\mathrm{L}$ and $\mathrm{E}$-shaped and its radiator size is very compact width $8 \mathrm{~mm}$ and length is $11.3 \mathrm{~mm}$. The author used Fr4 substrate and dielectric constant is 4.4 and size is $0.8 \mathrm{~mm}$. The proposed antenna has design with the help of SATIMO STARLAB simulator. The proposed antenna maximum gain is $5.1 \mathrm{dBi}$ and efficiency is $83 \%$.

In this paper [2] a new dual band antenna was proposed and analyzed. Such type of antenna had compact radiator for 2.4/5.2/5.8 GHz WLAN application. It is configured as an asymmetrical meandered $\mathrm{T}$-shaped monopole with a longand a short arm. Depending on relative length of the two arms, the short arm can be used to tune the resonant frequency and/or the bandwidth. Its radiator size is very compact width $28 \mathrm{~mm}$ and length is $33 \mathrm{~mm}$. The author used Fr4 substrate and dielectric constant is 4.4 and size is $1.6 \mathrm{~mm}$. The proposed antenna has design with the help of

IE3D simulator. The proposed antenna maximum gain is 1$3 \mathrm{dBi}$ and return loss is $-18 \mathrm{~dB}$.

In this paper [3] a new dual band antenna was proposed and analyzed. Such type of antenna had compact radiator for 2.4/5.2/5.8 GHz WLAN application. It is configured as dualwideband antenna formed by a triangular monopole and a Ushaped monopole is presented. The antenna can generate two wide bands centered at about $2.5 \mathrm{GHz}$ and $5 \mathrm{GHz}$ to cover all the 2.4/5.2/5.8 GHz WLAN bands and the 2.5/3.5/5.5 WiMAX bands. Its radiator size is very compact width $28 \mathrm{~mm}$ and length is $33 \mathrm{~mm}$.The author used Fr4 substrate and dielectric constant is 4.4 and size is

$1.6 \mathrm{~mm}$. The proposed antenna has design with the help of HFSS simulator. The proposed antenna maximum gain is 1$4.1 \mathrm{dBi}$ and return loss is $-38 \mathrm{~dB}$.

In this paper [4] design of a micro strip patch array antenna is proposed by optimization its resonant frequency, Bandwidth of operation and Radiation resistance using genetic algorithm. Its design work on 3-18 GHz frequency. The author used
Duroid substrate and dielectric constant is 2.39 and size is $1.524 \mathrm{~mm}$. The proposed antenna has design with the help of IE3D simulator. The proposed antenna Bandwidth is 25.52 and return loss is $22.649 \mathrm{db}$

\section{ANTENNA ARCHITECTURE DESIGN AND FORMULAS}

Microstrip patch antenna consist a radiating patch on one side of a dielectric substrate which has a ground plane on the other side. The two conductor separated by dielectric material looks like a transmission line. So transmission line model can be used for mathematical analysis of proposed antenna [10] [11]. When excitation is given to antenna then because of fringing field the effective length of the patch is increase. Thus, the actual length of patch is slightly less than the effective length of patch due to fringing effect. The electric field lines in the patch antenna mostly move in the substrate and even a bit out of the substrate in to the air, so the value of ereff is slightly less than that of $\varepsilon r$ [15] .

The effective dielectric constant (creff) is given as [15]: +

The change in length is calculated as: The width of proposed antenna can be calculated by using effective dielectric constant and wave length $=\mathrm{C} / \mathrm{f0}$ as:

$\mathrm{W}=$ The effective length (Leff) and actual length (L) of proposed antenna is calculated as:

Leff $=\& \quad \mathrm{~L}=$ Leff $-2 \Delta \mathrm{L}$

\section{GENETIC ALGORITHM}

Genetic Algorithms (GAs) are adaptive heuristic search algorithm depend on the evolutionary concepts of general selection and genetics. As such they present an intelligent exploitation of a arbitrary search utilized to solve optimization problems. Although randomized. GAs are by no means random, in place of that they utilize historical information to direct the search into the region of proper behavior under the search space. The general techniques of the GAs are created to imitate procedures in natural systems compulsory for evolution; specifically those pursue the principles first laid down by Charles Darwin of "survival of the fittest." Since in 
nature, competition between individuals for scanty resources provides in the fittest individuals influencing over the weaker ones.

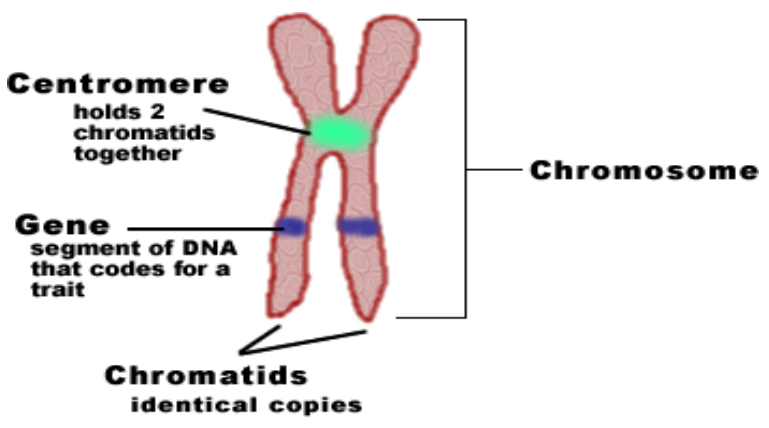

Fig.2 Structure and chromosome

\section{PROBLEM FORMULATION}

In base Paper and supporting paper [1-3] is used normal optimized method. Paper [2-4] is using $1.6 \mathrm{~mm}$ height and efficiency is poor. In this paper proposed less of the height and high efficiency using MATLAB and CST.

\section{CONCLUSION}

A dual-band monopole antenna accompanied by a very concise area only for $2.4 / 5.2 / 5.8-\mathrm{GHz}$ WLAN applications has been generated and studied by utilizing computer simulation and measurement. The antenna radiator consists of an E shaped and L-shaped components having resonances at about 2.44 and $5.5 \mathrm{GHz}$, respectively. The two frequency bands can be tuned independently. The S11, radiation pattern, gain and efficiency all have been studied. The feeding cable utilized in the measurement device has been represented by utilizing computer simulation. The simulation results by utilizing the feeding cable support very well accompanied by the calculated results.

\section{REFERENCES}

[1] Xiao Lei Sun,Li Liu, S.W. Cheung,T.I. Yuk Rodenbeck 2012. Dual-Band Antenna With Compact Radiator for 2.4/5.2/5.8 GHz WLAN Applications, IEEE Transactions on Antennas and Propagation, vol. 60, no. 12, December 2012

[2] Qing Xing Chu,Liang Hua ye article 2010. Design of Compact Dual-Wideband Antenna With Assembled Monopoles, IEEE Transactions on Antennas and Propagation, vol. 58, no. 12, December 2010

[3] The Nan Chang,Jing Hae Jiang 2009. Meandered TShaped Monopole Antenna, IEEE Transactions on Antennas and Propagation, vol. 57, no. 12, December 2009.

[4] Shibaji Chakraborty,Uddipan Mukherjee, Micro strip antenna optimization using Genetic Algorithms,978-14244-9034-/102010IEEE ICCCT’10.
[5] Takeshi Fukusako and Teruhisa Nakamura, "Broadband Design of Circularly Polarized Microstrip Patch Antenna Using Artificial Ground Structure With Rectangular Unit Cells" IEEE Trans. on Antennas and Propag., volume 59, NO.6, June 2011.

[6] Kaushik Mandal and Partha Prtim Sarkar "High Gain Wide-Band U-Shaped Patch Antennas With Modified Ground Planes”, IEEE Trans. on Antennas and Propag. , vol. 61, no.4,pp.2279-2282,April 2013.

[7] Ahmed Khidre, Kai-Fong Lee, Fan Yang, and Atef Z. Elsherbeni, "Wide Band Dual Beam U-Slot Microstrip Antenna", IEEE Trans. on Antennas and Propag. , vol. 61, no. 3, pp.1415-1418, March 2013.

[8] Juhua Liu and Quan Xue,'Broadband Long Rectangular Patch Antenna with High Gain and Vertical Polarization", IEEE Trans. on Antennas and Propag., volume 61, no.2, February 2013.

[9] Kwai-Man and Luk Mingjian Li," A Low-Profile Wideband Planar Antenna", IEEE Transactions on Antennas and Propagation, VOL. 61, NO. 9, pp.44114418, September 2013.

[10] Ahmed Khidre, Kai-Fong Lee, Fan Yang, and Atef Z. Elsherbeni "Circular Polarization Reconfigurable Wideband E-Shaped Patch Antenna for Wireless Applications",IEEE Trans. on Antennas and Propag. vol. 61, no.2, pp.960-965, February 2013.

[11] Jianyi Zhou and Wenwen Yang,"Wideband Low-Profile Substrate Integrated Waveguide Cavity-Backed EShaped Patch Antenna", IEEE Trans. on Antennas and Propag., vol.12, 2013.

[12] S. Bhunia," Effects of Slot Loading on Microstrip Patch Antennas", International Journal of Wired and Wireless Communications, volume 1, issue 1, October, 2012.

[13] S. T. Fan, Y. Z. Yin, B. Lee, "Bandwidth Enhancement of a Printed Slot Antenna with a Pair of Parasitic Patches IEEE Transactions on Antenna and Wireless Propag. vol. 11, 2012.

[14] D. M.Pozar, Microwave Engineering. New York: Addison-Wesley, 1990, p. 185.

[15] C. A. Balanis, Antenna Theory: Analysis and Design. New York: Wiley, 1997, p. 734.

\section{AUTHOR PROFILE}

Ramnath Narhete received her Bachelor's degree in Electronics and Communication Engineerin-g from NRI Institute of Information Science and Technology Bhopal, India in 2011.Currently he is pursuing her master of technology in digital communication from NRI Institute of Information Science and Technology Bhopal, India. He is founder of DSTARENA and BHOPAL BAZAR.com. His research interest is Antenna Design and Optimization. 